\title{
Early Impairment of Left Ventricular Function in Hypertensive Patients with Preserved Ejection Fraction using Tissue Doppler Echocardiography
}

\author{
Rezwana Siddique ${ }^{1}$, Tuhin Haque ${ }^{2}$, Md. Kabiruzzaman ${ }^{1}$, Sohel Reza Chowdhury ${ }^{3}$, Fazila-Tun- \\ Nesa Malik ${ }^{1}$, Mohammad Arifur Rahman ${ }^{4}$ \\ ${ }^{1}$ Department of Cardiology, National Heart Foundation Hospital and Research Institute, \\ Dhaka, ${ }^{2}$ Department of Echocardiography, National Heart Foundation Hospital and Research \\ Institute, Dhaka, ${ }^{3}$ Department of Epidemiology\& Research, National Heart Foundation Hospital and \\ Research Institute, Dhaka, ${ }^{4}$ Department of Cardiology, National Institute of Cardiovascular Diseases, \\ Dhaka.
}

\section{Key Words: Tissue doppler imaging, Left ventricular hypertrophy, Systolic annular velocity, Diastolic filling pressure, Heart failure, Hypertension.}

\begin{abstract}
:
Background: Hypertension is an emerging risk factor for developing heart failure with preserved ejection fraction (HFpEF). Diastolic dysfunction most frequently associated with a subclinical impairment of systolic function in patients with HFpEF. The aim of this study was to detect early impairment of left ventricular function in hypertensive patients with preserved ejection fraction using Tissue Doppler Imaging (TDI).

Methods: This cross-sectional study included a total 105 subjects who were divided into three groups (group-1: 35 healthy control; group-2: 35 hypertensive patients without concentric left ventricular hypertrophy, and group-3: 35 hypertensive patients with concentric left ventricular hypertrophy having left ventricular ejection fraction (LVEF) $>50 \%$ on $2 D$ echocardiography). They underwent TDI to measure systolic dysfunction by systolic annular velocity during systole ( $\left.S^{\prime}\right)$ and diastolic dysfunction by diastolic filling pressure ( $\left.E / E^{\prime}\right)$.

Results: The results were obtained in 105 subjects: group-1 (40.63土5.0years; $34.4 \%$ male); group-2

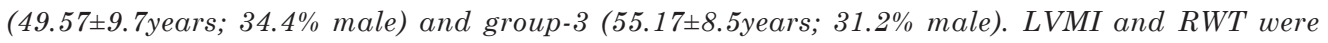
significantly higher $(p<0.001)$ in both hypertensive groups. The presence of systolic dysfunction by TDI as evidence by systolic annular velocity $\left(S^{\prime}\right)$ was significantly reduced $(p<0.001)$ in both

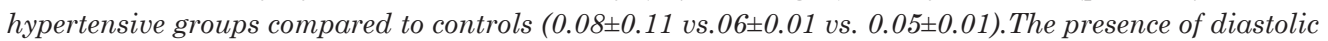
dysfunction by TDI as evidence by diastolic filling pressure $\left(E / E^{\prime}\right)$ were significantly higher $(p<0.001)$ in both groups of hypertensive patients. There was significant correlation between $E / E^{\prime}$ and $S^{\prime}(r=$ -593; $p=<0.001$ ).

Conclusion: TDI provided a new insight into impaired systolic function by detecting lower values of $S^{\prime}$ and impaired diastolic function by detecting higher values of $E / E^{\prime}$ in hypertensive patients. This study was a clear reflection of early impairment of $L V$ function in hypertensive patients (with or without $C-L V H)$ and it might be helpful for identifying hypertensive patients who are at high risk for heart failure.
\end{abstract}

(Cardiovasc.j. 2017; 9(2): 147-154)

\section{Introduction:}

Hypertension (HTN) or high blood pressure is a major risk factor for cardiovascular disease. ${ }^{1}$ Globally approximately 7.6 million premature deaths annually and $6 \%$ of the global burden of disease is attributable to HTN. In the Framingham Heart Study, about $90 \%$ of new cases of heart failure (HF) had a history of previous hypertension. HTN is highly prevalent in Bangladesh. It is estimated that 12 million people living with HTN in Bangladesh. ${ }^{2}$ This is emerging that the high prevalence of HTN contribute to a large percentage of heart failure with preserved ejection fraction (HFpEF). ${ }^{3}$ Recent research on heart failure with normal ejection fraction (EF) has demonstrated that diastolic dysfunction most frequently associated with a subclinical impairment of systolic function. ${ }^{4}$ Population based epidemiological

Address of Correspondence: Dr. Rezwana Siddique, Department of Cardiology: National Heart Foundation Hospital and Research Institute, Dhaka, Bangladesh. Email:dr.rezwanasiddique25@gmail.com. 
echocardiographic studies report that approximately $40 \%$ to $50 \%$ of all $\mathrm{HF}$ cases have HFpEF which accounts for the morbidity and mortality similar to that of patients with reduced ejection fraction (HFrEF). ${ }^{5}$ The conventional 2D echocardiography can detect changes in left ventricular (LV) diastolic dysfunction but the systolic dysfunction has been unrevealed due to presence of preserved ejection fraction (EF) in the early stage of hypertensive heart disease (HHD). Early detection of LV systolic dysfunction in hypertensive patients with preserved EF is one of the current interest. ${ }^{6}$ The pathophysiological model of $\mathrm{HFpEF}$ focuses on the presence of diastolic dysfunction due to abnormalities of relaxation and / or increased of LV stiffness. LVEF is the most widely used index to assess cardiac systolic function but it is influenced by preload, post load, heart rate, myocardial contractility and dyssynchrony. ${ }^{7}$ The distribution of myocardial fibers is not uniform throughout the LV wall. The bundles of subendocardial and subepicardial muscles are arranged longitudinally, while the fibers located in the middle of the wall are aligned circumferentially. This group of muscle fibers is primarily responsible for $\mathrm{LV}$ radial axis contraction. As the fibers of the longitudinal axis be measured by the movement of the heart base correspond to the atrioventricular ring (AR), change in the longitudinal axis can be measured by the movement of the AR ring through TDI (S'). ${ }^{8}$ Structural changes in the in the myocardium, such as altered collagen and myocardial cells, are probably the mechanism of diastolic dysfunction which were associated with impaired diastolic tissue Doppler parameters. ${ }^{9}$ TDI, has recently provides a useful index, which can detect even very slight impairment of LV function that cannot be identified by EF.TDI has emerged as an echocardiographic technique for bedside noninvasive analysis of measuring the changes in the longitudinal axis by the movement of the AR ring through TDI ( $\mathrm{S}^{\prime}$ ) which has a good relationship with global systolic functions. ${ }^{8}$ For the detection of diastolic dysfunction the ratio between the transmitral E velocity and pulsed tissue Doppler derived LV filling index by early diastolic velocity( the E/ $\mathrm{E}^{\prime}$ ratio)has been identified as the most accurate for the detection of heart failure with preserved EF. ${ }^{10}$

\section{Methods:}

A cross -sectional control study was conducted from November 2014 to October 2015 with essential hypertensive patients without sign or symptom of heart failure with normal ejection fraction (LVEF $>50 \%$ ) with no regional wall motion abnormality (RWMA) at rest by conventional 2D echocardiography during the course of hospitalization or visiting cardiology outpatient department (OPD) at National Heart Foundation Hospital and Research Institute, Dhaka. Patients with secondary hypertension, significant valvular heart disease (more than mild) and congenital heart disease and patient with associated disease (DM, CKD, IHD, CLD, Arrhythmia, and Malignancy) were excluded. Control groups were selected from the patient visiting cardiology OPD and the volunteer control from doctors, nurses and their relatives having no significant disease after going through clinical evaluation. The study population divided after performing 2D Echocardiography into 3 groups-

Group-1 (35 subjects): Normotensive volunteers / Healthy control and the hypertensive patients then divided into two subgroups according to the echocardiographic criteria of LVH: Group-2 (35 subjects) included hypertensive patients without LVH, and group-3(35 subjects) included hypertensive patients with LVH. Informed consent was taken from each subject before enrolment. Meticulous history and detailed clinical examination was performed in each subjects. Demographic data such as age, sex, height $(\mathrm{cm})$, weight $(\mathrm{kg})$, BMI $(\mathrm{kg} / \mathrm{m} 2)$ and BSA $\left(\mathrm{m}^{2}\right)$ were calculated by a standard transthoracic echocardiography (TTE). Before TTE, blood pressure of the subjects was measured using a conventional sphygmomanometer in sitting position. Baseline 12 lead ECG of the subjects was performed.

\section{Conventional 2D M Mode Echocardiography:}

Conventional Two-dimensional (2D) echocardiography was performed with grayscale harmonic images were obtained in the left lateral position using a commercially available ultrasound system Vivid E9 (GE health care, Horten, Norway) equipped with a cardiac 3.5-MHZ transducer in the parasternal (long and short axis images) and apical ( 2 and 4 chamber image) views and connected 
to single lead ECG. 2D and color Doppler imaging were performed to screen for wall motion abnormalities, mitral annular calcification, valvular stenosis and regurgitation. LV wall thickness, diameters, volumes and EF (Teichholz method) were measured at M-mode according to the American Society of Echocardiography (ASE) recommendations.

Assessment of concentric hypertrophy was based on LVMI $\left(\mathrm{g} / \mathrm{m}^{2}\right)$ and RWT (\%).The end-diastolic relative wall thickness (RWT) was also calculated, and a cut-off value of $\geq 0.42$ was taken into account to define a concentric hypertrophy. The LV mass index calculated as ratio $\mathrm{LV}$ mass $/ \mathrm{BSA}\left(\mathrm{g} / \mathrm{m}^{2}\right)$. The diagnosis of LV hypertrophy was based on a LV mass index (LVMI) $>115 \mathrm{~g} / \mathrm{m}^{2}$ in men and $>95 \mathrm{~g} / \mathrm{m}^{2}$ in women. ${ }^{12}$ Trans-mitral pulsed-wave Doppler recorded with early diastolic filling (E), late diastolic filling (A), and E/A ratio and early diastolic flow deceleration time (DT) was calculated to measure diastolic function.

Color TDI acquired at both four- and two-chamber views, obtained at end-expiratory apnea, were digitally stored. Gain was minimized to have a clear tissue signal with minimal background noise. To acquire the highest tissue velocities, the angle between the Doppler beam and mitral annulus adjusted to a minimal level $\left(<20^{\circ}\right)$. A Pulsed Wave Doppler sample was set, at the level of the septal corner (apical four-chamber view) of mitral annulus. The peak of systolic mitral annular velocity ( $\left.\mathrm{S}^{\prime}\right)$, early diastolic velocity $\left(\mathrm{E}^{\prime}\right)$ and late diastolic velocity (A') were calculated and E/É ratio was calculated. Data was collected in a predesigned data collection form. The research was approved by the Ethics Committee of NHF\& RI, Dhaka.

\section{Statistical analysis:}

After processing of all available data were presented with summarized descriptive tables and figures and statistical analysis was done with the help of computer based SPSS (Statistical programme for social science) programme version 16.0. P-value of $<0.05$ was considered significant. Continuous variable with normal distribution were expressed as Mean \pm Standard deviation by one way analysis of variance (ANOVA). An additional post-hoc analysis by Bonferroni's correction was done for comparison between groups. Categorical variables were expressed in absolute number and percentage and were analyzed by Chi-square test and Fisher's exact test. Pearson's coefficient was used.

\section{Results:}

Over the one year, total 105 subjects fulfilling the inclusion and exclusion criteria were underwent TDI. The main demographic and clinical characteristics of study population are presented in Table-I. In hypertensive patients with preserved ejection fraction we observed an elder group (40.63 \pm 5.01 vs. $49.57 \pm 9.79 v$ v $55.17 \pm 8.55)$. There was significant difference among the three groups regarding systolic and diastolic blood pressure $(\mathrm{p}<0.001)$ There was no statistically significant difference regarding sex among three groups of study populations $(\mathrm{p}=0.548)$.

Table-I

Distribution of the study population according to demographic and clinical characteristics $(n=105)$.

\begin{tabular}{lcccc}
\hline Variables & $\begin{array}{c}\text { Group-1 }(\mathrm{n}=35) \\
\text { Normotensive } \\
\text { healthy } \\
\text { control }\end{array}$ & $\begin{array}{c}\text { Group-2 }(\mathrm{n}=35) \\
\text { Hypertensive } \\
\text { without } \\
\text { concentric } \\
\text { hypertrophy }\end{array}$ & $\begin{array}{c}\text { Group-3(n=35) } \\
\text { Hypertensive } \\
\text { With concentric } \\
\text { hypertrophy }\end{array}$ & \\
& Mean $\pm \mathrm{SD}$ & $49.57 \pm 9.79$ & Mean $\pm \mathrm{SD}$ & \\
\hline Age $(\mathrm{yrs})$ & $40.63 \pm 5.01$ & $162.00 \pm 10.72$ & $159.17 \pm 8.55$ & $<0.001^{\mathrm{S}}$ \\
Height $(\mathrm{cm})$ & $160.89 \pm 9.43$ & $67.91 \pm 14.13$ & $66.14 \pm 11.11$ & $0.624^{\mathrm{NS}}$ \\
Weight $(\mathrm{Kg})$ & $63.46 \pm 8.79$ & $1.74 \pm 0.27$ & $1.68 \pm 0.17$ & $0.272^{\mathrm{NS}}$ \\
$\mathrm{BSA}\left(\mathrm{M}^{2}\right)$ & $1.67 \pm 0.14$ & $25.65 \pm 3.13$ & $25.78 \pm 3.64$ & $0.394^{\mathrm{NS}}$ \\
$\mathrm{BMI}\left(\mathrm{Kg} / \mathrm{M}^{2}\right)$ & $24.54 \pm 1.87$ & $129.86 \pm 10.60$ & $134.29 \pm 12.72$ & $<0.165^{\mathrm{NS}}$ \\
$\mathrm{SBP}(\mathrm{mm} \mathrm{Hg})$ & $112.71 \pm 9.87$ & $84.57 \pm 5.19$ & $86.71 \pm 6.17$ & $<0.001^{\mathrm{S}}$ \\
$\mathrm{DBP}(\mathrm{mm} \mathrm{Hg})$ & $74.57 \pm 6.79$ & &
\end{tabular}


Table-II displayed the 2D M-mode echocardiographic parameters. The global systolic function was measured through LVEF and there were no difference between study population when systolic function were assessed in the radial axis by measuring the LVEF $(64.25 \pm 2.83$ vs64.52 $\pm 4.29 \mathrm{vs} 64.54 \pm 4.34 ; \mathrm{p}=0.939)$. Expectedly, there were statistically significant difference $(p<0.001)$ were observed among three groups in respect to LVPWTD $(9.00 \pm 1.0 \mathrm{~mm}$ vs. 10.14 $\pm 1.0 \mathrm{~mm}$ vs. $12.65 \pm 1.0 \mathrm{~mm})$ and IVSTD $(8.97 \pm 1.0$ $\mathrm{mm}$ vs. $10.11 \pm 0.9 \mathrm{~mm}$ vs. $12.77 \pm 1.1 \mathrm{~mm})$. Meanwhile, our study showed that the mean LVMI were $71.10 \pm 11.84 \mathrm{gm} / \mathrm{m}^{2}, 83.31 \pm 14.63 \mathrm{gm} / \mathrm{m}^{2}$ and $132.41 \pm 23.50 \mathrm{gm} / \mathrm{m}^{2}$ in group-1, group-2, and group-3 respectively which was statistically significant $(p<0.001)$. There were statistically significant difference $(\mathrm{p}<0.001)$ in relative wall thickness $(0.41 \pm 0.0 \%$ vs. $0.46 \pm 0.0 \%$ vs. 0.57 $\pm 0.0 \%)$.
The assessment of LV systolic function in the longitudinal axis by measuring systolic annular velocity ( $\mathrm{S}^{\prime}$ ) were statistically significant $(\mathrm{p}<0.001)$ among three groups in our study $(0.08 \pm 0.0 \%$, vs. $0.06 \pm 0.0 \%$ vs. $0.05 \pm 0.0 \%$ ) which was shown in TableIII. The values of systolic annular velocity ( $\mathrm{S}^{\prime}$ ) among study population were shown in Figure-1.

Diastolic dysfunction was present in $11.4 \%$ in group-1, $91.4 \%$ in group-2 and $97.1 \%$ in group-3, which were statistically significant $(p<0.001)$ shown in Figure-2.In Table- 4 indicated that the LV diastolic impairment was common in hypertensive patients, as shown by decrease of the E/A ratio $(1.45 \pm 0.26$ vs $1.12 \pm 0.27$ vs $0.79 \pm 0.18 ; \mathrm{p}<0.001) . \mathrm{LV}$ diastolic function evaluated by TDI were significantly different for parameters that assess $\mathrm{LV}$ filling pressure $\mathrm{E} / \mathrm{E}^{\text {' }}$ ratio $(7.64 \pm 1.14 \mathrm{vs}$. $10.45 \pm 1.92$ vs. $11.86 \pm 1.93)$. There was an increase value of $\mathrm{E} / \mathrm{E}^{\text {' }}$ ratio, in both hypertensive groups in comparison to control, although it was more evident in hypertensive with concentric LVH.

\section{Table-II}

2D M-Mode Echocardiographic parameters of the study population ( $n=105)$.

\begin{tabular}{lcccc}
\hline Parameters & $\begin{array}{c}\text { Group-1 }(\mathrm{n}=35) \\
\text { Normotensive } \\
\text { control }\end{array}$ & $\begin{array}{c}\text { Group-2 }(\mathrm{n}=35) \\
\text { Hypertensive } \\
\text { without } \\
\text { concentric } \\
\text { hypertrophy } \\
\text { Mean } \pm \text { SD }\end{array}$ & $\begin{array}{c}\text { Group-3(n=35) } \\
\text { Hypertensive } \\
\text { with } \\
\text { concentric } \\
\text { hypertrophy } \\
\text { Mean } \pm \text { SD }\end{array}$ & \\
& Mean \pm SD & $42.77 \pm 4.4$ & $43.20 \pm 5.5$ & \\
\hline $\operatorname{LVEDD~}(\mathrm{mm})$ & $43.02 \pm 3.2$ & $10.14 \pm 1.03$ & $12.65 \pm 1.05$ & $0.923^{\mathrm{NS}}$ \\
$\operatorname{LVPWTD}(\mathrm{mm})$ & $9.00 \pm 1.02$ & $10.11 \pm 0.99$ & $12.77 \pm 1.11$ & $<0.001^{\mathrm{S}}$ \\
IVSTD $(\mathrm{mm})$ & $8.97 \pm 1.07$ & $0.46 \pm 0.06$ & $0.57 \pm 0.09$ & $<0.001^{\mathrm{S}}$ \\
$\operatorname{RWT}(\%)$ & $0.41 \pm 0.04$ & $64.52 \pm 4.29$ & $64.54 \pm 4.34$ & $<0.001^{\mathrm{S}}$ \\
$\operatorname{LVEF}(\%)$ & $64.25 \pm 2.83$ & $83.31 \pm 14.63$ & $132.41 \pm 23.50$ & $0.939^{\mathrm{NS}}$ \\
$\operatorname{LVMI}\left(\mathrm{gm} / \mathrm{m}^{2}\right)$ & $71.10 \pm 11.84$ & & & $<0.001^{\mathrm{S}}$ \\
\hline
\end{tabular}

\section{Table-III}

Distribution of study population according to systolic function by Color Doppler and TDI ( $n=105)$.

\begin{tabular}{lcccc}
\hline Parameters & $\begin{array}{c}\text { Group-1 }(\mathrm{n}=35) \\
\text { Normotensive } \\
\text { control }\end{array}$ & $\begin{array}{c}\text { Group-2 }(\mathrm{n}=35) \\
\text { Hypertensive } \\
\text { without concentric } \\
\text { hypertrophy } \\
\text { Mean } \pm \mathrm{SD}\end{array}$ & $\begin{array}{c}\text { Group-3 }(\mathrm{n}=35) \\
\text { Hypertensive } \\
\text { with concentric } \\
\text { hypertrophy } \\
\text { Mean } \pm \mathrm{SD}\end{array}$ & ${ }^{*} \mathrm{P}$ \\
\hline $\mathrm{S}^{\prime}(\mathrm{m} / \mathrm{s})$ & $0.08 \pm 0.11$ & $0.06 \pm 0.01$ & $0.05 \pm 0.01$ & $<0.001^{\mathrm{S}}$ \\
\hline
\end{tabular}




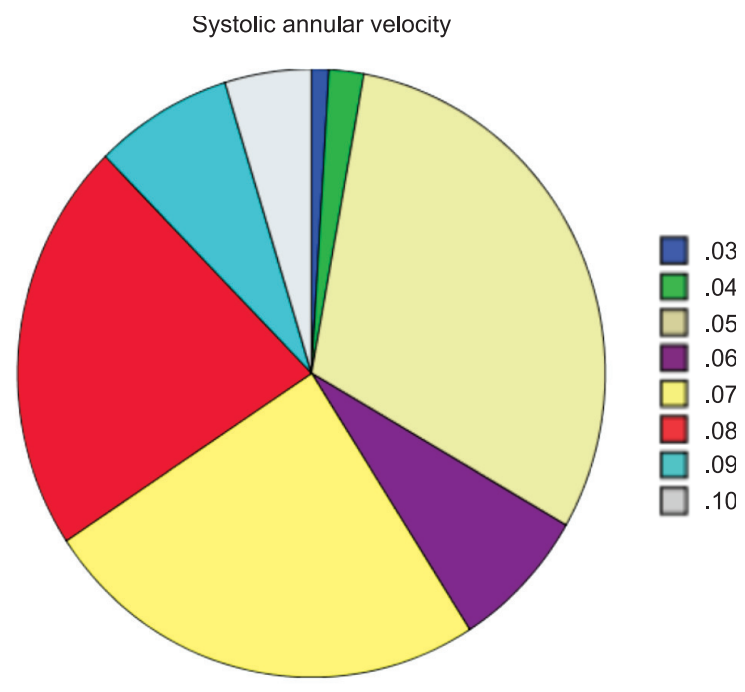

Fig-1: Distribution of systolic annular velocity $\left(S^{\prime}\right)$ among study population using Color Doppler and TDI.

\section{Table-IV}

Distribution of the study population according to diastolic function by color Doppler and TDI ( $n=105)$

\begin{tabular}{lcccc}
\hline Parameters & $\begin{array}{c}\text { Group-1 }(\mathrm{n}=35) \\
\text { Normotensive } \\
\text { control }\end{array}$ & $\begin{array}{c}\text { Group-2 }(\mathrm{n}=35) \\
\text { Hypertensive patient } \\
\text { without concentric } \\
\text { hypertrophy } \\
\text { Mean } \pm \mathrm{SD}\end{array}$ & $\begin{array}{c}\text { Group-3 }(\mathrm{n}=35) \\
\text { Hypertensive } \\
\text { with concentric } \\
\text { hypertrophy } \\
\text { Mean } \pm \mathrm{SD}\end{array}$ & $* \mathrm{P}$ \\
\hline E/A ratio & Mean $\pm \mathrm{SD}$ & Mean $\pm \mathrm{SD}$ & Mean $\pm \mathrm{SD}$ & \\
E/E' ratio & $1.45 \pm 0.26$ & $1.12 \pm 0.27$ & $0.79 \pm 0.18$ & $<0.001^{\mathrm{S}}$ \\
\hline
\end{tabular}

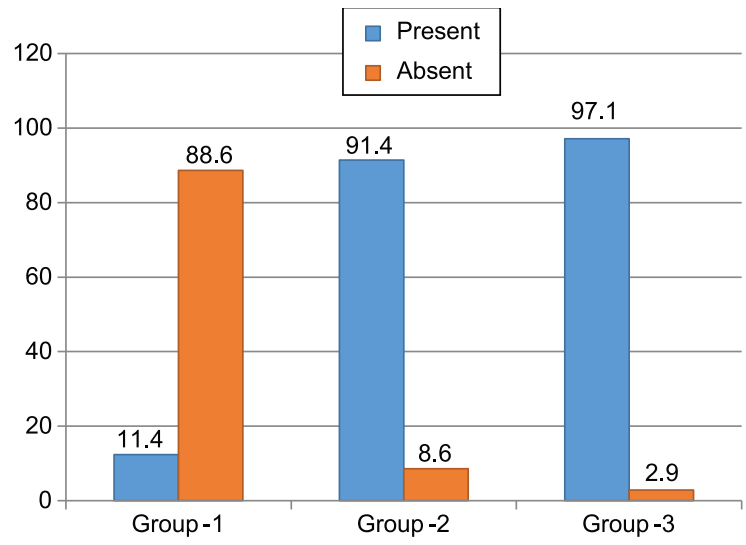

Fig-2: Distribution of the study population according to diastolic dysfunction using Color Doppler and TDI $(n=105)$.

Figure-3 showed that there was a linear correlation between the systolic function $\left(\mathrm{S}^{\prime}\right)$ and diastolic dysfunction (E/E'). Our finding also showed that systolic annular velocity ( $\left.\mathrm{S}^{\prime}\right)$ correlated significantly with diastolic filling pressure $\left(\mathrm{E} / \mathrm{E}^{\prime}\right)$ $(\mathrm{r}=-0.593 ; \mathrm{p}<0.001)$ revealing a strong link between $\mathrm{LV}$ contraction and relaxation with normal EF in hypertensive patients.

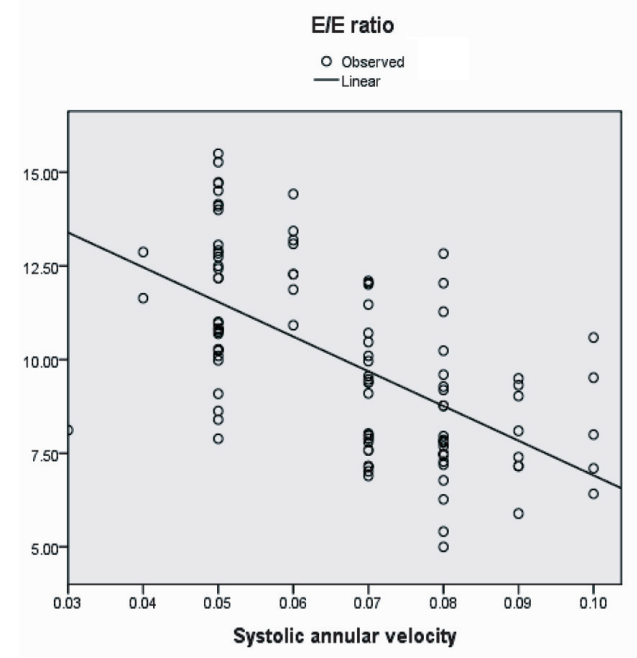

Fig-3: Linear Correlation of systolic and diastolic parameters by $S^{\prime}$ and $E / E^{\prime}$ using Color Doppler and TDI. 


\section{Discussion:}

The principal objective of this study was to detect early impairment of LV function in hypertensive patients (with or without C-LVH) with preserved ejection fraction using TDI.

In this study, the parameters of LVMI and RWT were significantly higher in hypertensive groups with preserved EF. Patients with hypertensive heart disease usually present with concentric remodeling or concentric LVH but have a normalsized LV chamber and normal EF. ${ }^{13}$ PrzewlockaKosmala, et al., stated that, LVMI, IVSTD and LVPWTD were significantly higher hypertensive patients than control. ${ }^{14}$

Due to the orientation of LV muscle fibers, when the LV contracts, it promotes a rotational motion that builds energy and during diastole, the energy stored is released, promoting a diastolic suction that contributes to the LV filling in the next cardiac cycle. Even small changes in the systolic function, not detected by LVEF measurement, may change ventricular contraction leading to a decreased relaxation and loss of suction that affects quick LV filling. New mechanistic discussions by the means of TDI that assess mechanisms of LV contraction and relaxation, allow a better understanding of the link between systole and diastole in the normal heart with preserved EF. ${ }^{15}$

High blood pressure promotes a gradual diastolic dysfunction along with the progression of concentric remodeling and hypertrophy. Various studies had suggested that complex interactions between cellular hyperplasia, cell death, fibrosis and reduced calcium uptake, together with increased myocardial stiffness, may be responsible for diastolic dysfunction in hypertensive individuals, particularly hypertensive patients with LVH while other authors argued that diastolic dysfunction may be an early marker of hypertensive heart disease. These results were in agreement as reported by Federico, et al., who also noted that LV diastolic dysfunction in patients with hypertension may occur before the development of hypertrophy and provided evidence that LVH is a pathological condition and constitute a major risk factor for subsequent heart decompensation and chronic heart failure. ${ }^{16}$

LV diastolic function evaluated by early diastolic mitral annular velocities can reflect an abnormal
$\mathrm{LV}$ relaxation ( $\left.\mathrm{E}^{\prime}\right)$ as well as elevated $\mathrm{LV}$ filling pressure (E/E') through TDI. Combining transmitral flow velocity with annular velocity (E/ $\left.\mathrm{E}^{\prime}\right)$ might be an index for estimating the LV filling pressure to detect diastolic dysfunction in the presence of preserved EF. The majority of hypertensive patients with elevated LV end diastolic filling pressure in the presence of normal $\mathrm{EF}$ as determined in several studies by invasive pressure-volume loops and had an $\mathrm{E} / \mathrm{E}^{\prime}$ ratio between 8 and 15 by TDI. ${ }^{13}$ There were significant differences in diastolic dysfunction among the three groups (control, hypertensive without LVH and hypertensive with hypertrophy) using the tissue Doppler measurement of E/E'. ${ }^{17}$ The findings of this present study indicated that the LV diastolic impairment was common in hypertensive patients, as shown by decrease of the $\mathrm{E} / \mathrm{A}$ and higher values of $\mathrm{E} / \mathrm{E}^{\prime}$ in comparison to control, although it was more evident in hypertensive with concentric LVH.

In asymptomatic hypertensive patients with preserved $\mathrm{EF}$, there was a reduction in the systolic tissue velocity of the long axis ( $\mathrm{S}^{\prime}$ ) which can be identified associated with diastolic dysfunction. ${ }^{10} \mathrm{~S}^{\prime}$ has the advantage of simple measurement, which is easily detectable in most patients and has high reproducibility. Most studies point out to the relative independence of pre and post load in $\mathrm{S}^{\prime}$ and $S^{\prime}$ is a marker of early systolic dysfunction in hypertension. ${ }^{18}$ Yip, et al. observed that the peak systolic mitral annular velocity by TDI was lower in patients with LV hypertrophy and diastolic dysfunction as compared with normal subjects which were similar to our study. ${ }^{19}$ The mean systolic annular velocities ( $\left.\mathrm{S}^{\prime}\right)$ were significant lower among the hypertensive groups in our study. This study highlighted the advantage of TDI in early identifying the longitudinal LV systolic function impairment. The finding was consistent with the results of a recent study of asymptomatic HF patient with hypertension, where LV longitudinal systolic function progressively deteriorates from NYHA Class I to IV and that circumferential systolic impairment occurs only in symptomatic patients (NYHA Class III and IV). ${ }^{4}$

Nikitin et al. evaluated patients with heart failure and normal global systolic function, $\mathrm{E}^{\prime}$ and $\mathrm{S}^{\prime}$ were lower, whereas E/É ratio was higher as compared 
with normal subjects which were similar to our result. ${ }^{20}$ Redfield, et al. also concluded with impaired diastolic function with decrease systolic annular velocity in hypertensive with preserved ejection fraction. ${ }^{14}$ Our results were similar to those of Tan, et al. which showed that patients HFpEF have abnormalities of LV systolic and diastolic function and $\mathrm{HFpEF}$ is not an isolated disorder of diastolic function. ${ }^{21}$ Assessment of systolic and diastolic dysfunction in hypertensive patients with preserved EF by TDI may provide important diagnostic information in this study.

Global systolic function assessed in the radial axis is preserved in the hypertensive patients with preserved $\mathrm{EF}$, as noted by the LVEF above $50 \%$.In the present study, there was a reduced contractility in the longitudinal axis measured by significant lower values of $\mathrm{S}^{\prime}$ identifying subclinical left ventricular systolic dysfunction and diastolic dysfunction was present as evidenced by higher values of $\mathrm{E} / \mathrm{E}^{\prime}$ in hypertensive patients (with or without C-LVH) with preserved EF. The limited sensitivity of global EF as demonstrated by Edvardsen et al. who stated that the apparently normal systolic function in heart failure with preserved EF. ${ }^{14}$ These findings were a clear reflection of presence of $\mathrm{LV}$ remodeling process in hypertensive heart disease and an early impairment of $\mathrm{LV}$ function in asymptomatic hypertensive patients despite $\mathrm{EF}$ was maintained within normal range.

\section{Study Limitation:}

Data was collected from single tertiary hospital and may not reflect the general population in Bangladesh and the measurements of TDI were angle dependent.

\section{Conclusion:}

The present study provided a new insight into impaired systolic function by detecting lower values of ' $\mathrm{S}^{\prime}$ and impairment of diastolic function by detecting higher values of $\mathrm{E} / \mathrm{E}^{\prime}$ which help to detect subclinical LV dysfunction of hypertensive patients with preserved ejection fraction and identify hypertensive patients who are at high risk for development of heart failure. This study will provide a prognostic validation for heart failure staging in hypertensive patients without C-LVH are being in stage A (risk factor) or hypertensive patients with $\mathrm{C}-\mathrm{LVH}$ are being in stage $\mathrm{B}$ (asymptomatic ventricular dysfunction).

\section{Acknowledge:}

I would like to express my thankful acknowledge to all participants for their willing participation and valuable information.

\section{Conflict of Interest - None.}

\section{References:}

1. Goncalves S, Dias NC, Nunes A, Belo A, Cabrita IZ, Sousa C, et al. Left ventricular systolic dysfunction detected by speckle tracking in hypertensive patients with preserved ejection fraction. Portuguese Journal of Cardiology 2014; 33: 27-37.

2. Alam DS, Chowdhury MAH, Siddiquee AT, Ahmed S and Niessen LW. Awareness and control of hypertension in Bangladesh: follow-up of a hypertensive cohort. Bangladesh Medical Journal 2014; 4: doi: 10.1136/bmjopen-2014-004983.

3. Bui AL, Horwich TB and Fonarow GC. Epidemiology and risk profile of heart failure. National Review of Cardiology 2011; 8(1): 30-41.

4. Imbalzano E, Zito $\mathrm{C}$ and Carerj $\mathrm{S}$, et al. Left ventricular function in hypertension: new ýnsight by speckle tracking echocardiography. Echocardiography 2011; 28: 649-657.

5. McGrady M, Reid CM, Shiel L, Wolfe R, Boffa U, Liew $\mathrm{D}$, et al. N-terminal B-type natriuretic peptide and the association with left ventricular diastolic function in a population at high risk of incident heart failure: results of the Screening Evaluation of the Evolution of New Heart Failure Study (SCREEN-HF). Eur J Heart Fail 2012; 15: 573-580.

6. Zile MR, Baicu CF, Gaasch WH. Diastolic heartfailureabnormalities in active relaxation and passive stiffness of the ventricle. N Engl J Med 2004; 50 (19): 1953-1959.

7. Mouhebati M, Fazlinejhad A and Yadollahi M. Tissue Doppler imaging in the assessment of myocardial systolic and diastolic functions in patients with stable angina pectoris. Revista Clinica de Medicinia de Familia 2014; 1(3): 125-130.

8. Sanderson JE and Fraser AG. Systolic dysfunction in heart failure with a normal ejection fraction: echo-Doppler measurements. Progress Cardiovascular Disease 2006; 49 (3): 196206.

9. Alam M, Wardell J, Andersson E, Samad BA, Nordlander R. Effects of first myocardial infarction on left ventricular systolic and diastolic function with the use of mitral annular velocity determined by pulse-wave Doppler tissue imaging. J Am Soc Echocardiog 2000; 13(5): 343-452. 
10. Karabinos I, Grasos C, Kostaki P and Kranidis A. Echocardiography in the Evaluation of a Hypertensive patient: An Invaluable Tool or Simply Following the Routine. Hellenic Journal of Cardiology 2013; 54: 47-57.

11. Hristova K and Shiue I. The Role of Echocardiography for Evaluation patients with Arterial Hypertension. Annals of Clinical and Experimental Hypertension 2014; 3(1): 1-6.

12. Lang RB, Afilalo J, Flachskampf FA, Kuznetsova T, Picard MH, Badano LP, et al. Recommendations for Cardiac Chamber Quantification by Echocardiography in Adults: An Update from the American Society of Echocardiography and the European Association of Cardiovascular Imaging. J Am Soc Echocardiog 2015; 28: 1-39.

13. Kuznetsova T, Herbots L, Jin Y, Staessen JA. Systolic and Diastolic Left Ventricular Dysfunction :Risk Factors to Overt Heart Failure. Expert Reviews Cardiovascular Therapy 2010; 8(2): 251-258.

14. Monaster SS, Ahmed MK, Braik AG. Comparison between strain and strain rate in hypertensive patients with and without left ventricular hypertrophy: a speckletracking study. Menoufia Medical Journal 2014; 27: 322-328.

15. Marwick TH, Leano RL, Brown J, Sun JP, Hoffmann $\mathrm{R}$, Lysyansky $\mathrm{P}$, et al. Myocardial strain measurement with 2-dimensional speckle-tracking echocardiography: definition of normal range. J Am Coll Cardiol Img 2009; 2: 80-84.
16. Federico C, Eleonora M, Raffaele M, Fulvio C, Giuseppe CMD, Giovanna NMD. Left ventricular function in the successive phases of systemic hypertension evaluated withpulsed doppler echocardiography. Heart Views 2007; 8(2): 34-39.

17. Rovner A, Fuentes L, Waggoner AD, Memon N, Chohan $\mathrm{R}$ and Dávila-Román VG. Characterization of left ventricular diastolic function in hypertension by use of Doppler tissue imaging and color M-mode techniques. J Am Soc Echocardiog 2006; 19: 872-879.

18. Borges MC, Colombo RC, Goncalves JG, Ferreira JdeO. Franchini KG. Longitudinal mitral annulus velocities are reduced in hypertensive subjects with or without left ventricle hypertrophy. Hypertension 2006; 47(5): 854-860.

19. Yip G, Zhang Y and Tan P, et al. Left ventricular longaxis changes in early diastole and systole: Impact of systolic function on diastole. Clinical Science (Lond) 2002; 102: 515-522.

20. Nikitin NP, Witte KK, Clark AL and Cleland JG. Color tissue Doppler derived long-axis left ventricular function in heart failure with preserved global systolic function. Am J Cardiol 2002; 90: $1174-1177$.

21. Tan YT, Wenzelburger F, Lee E, Heatlie G, Leyva F. Exercise echocardiography reveals complex abnormalities of both systolic and diastolic ventricular function involving torsion, untwist, and longitudinal motion. J Am Coll Cardiol 2009; 54(1): 36-46. 